\title{
A Study of the Relationship of Personality Types and Emotional Intelligence: A Case Study of the Undergraduates of University of Sri Jayewardenepura
}

\author{
Mallikaarachchi, CD and Arachchige, BJH
}

\begin{abstract}
Area of the Study

The current research is focused on the relationship of the big five personality types and emotional intelligence of the university of Sri Jayewardenepura. Even though, there has been a plenty of international studies focusing on this research area, in the context of Sri Lanka there is little evidence to be found. Therefore this study is filling the empirical gap of the respective study area
\end{abstract}

\section{Problem of the Study}

The main objective of the research is to find out whether there is a relation between personality and emotional intelligence. Thus the problem statement of this study is, "Is there a strong relationship between personality and emotional intelligence with regard to the university undergraduates in Sri Lanka?"

\section{Method of the Study}

To collect data for this study 77 item questionnaire was used and it was consisted with 5 point Likert scale. Data was analyzed using correlation and regression analysis with the SPSS (16.0 versions). The data were collected from 172 management undergraduates.

\section{Findings of the Study}

It was found that the overall big five personality has a positive relationship with the emotional intelligence of the university undergraduates.

\section{Conclusion of the Study}

It was found that the overall big five personality dimensions positively correlated with the emotional intelligence except neuroticism. The results of the multiple regression analysis showed that the big five personality model can predict the variance of emotional intelligence by nearly $41 \%$.

Keywords: Big Five Personality, Emotional Intelligence, Sri Lankan Undergraduates, Big Five Inventory

\section{Introduction}

Personality is a well established and frequently discussed concept in the literature of Human Resource Management, Organizational Behavior and Psychology (Opatha 2007). However there are many accepted definitions given by practitioners and academics for personality. As cited in (Opatha 2007) the concept of personality is defined by Dunham (1984 p. 221) as "Personality distinguishes you from other people and defines your general nature. Your overall personality is composed of a collection of psychological characteristics or traits which determines your personal preferences and individual style of behaviour." Accordingly the personality differentiates one individual from another individual and it is the general 
nature of an individual. Individual's overall personality is consisted of a set of psychological characteristics or traits and those psychological characteristics would determine the individual's personal preference and the style of behaviour.

There are a plenty of personality trait models in the literature of psychology and organizational behaviour namely the Myers-Briggs Type Indicator (MBTI), which is based on Jungian psychological type theory (Bradley \& Hebert 1997; Leary et al. 2009), Core self evaluation which includes self esteem, general self efficacy, emotional stability and internal locus of control (Alarcon et al. 2009). Among them the contribution made to industrial and organizational psychology by Big Five Personality Trait Model is significant (Kim et al. 2007). The figure 1 summarizes the five personality types and the distinct features of each personality type (Bakker et al. 2006; Kim et al. 2007).

Figure 1: Big Five Personality Model and Distinct Features

\begin{tabular}{ll}
\hline Personality Type & Distinct Features \\
\hline Extraversion & $\begin{array}{l}\text { self confident, dominant, active, positive emotions, } \\
\text { high personal interaction, optimistic, sociable, } \\
\text { gregarious, talkative } \\
\text { Altruism, nurturance, caring, warmth, friendliness, kindness, } \\
\text { empathy in social interactions, being courteous, trusting, } \\
\text { sgreeableness }\end{array}$ \\
$\begin{array}{l}\text { self discipline, achievement striving, dutifulness, } \\
\text { competence }\end{array}$ \\
$\begin{array}{l}\text { experience negative \& distressing emotions, } \\
\text { fearfulness, irritability, low self-esteem, social } \\
\text { anxiety, poor inhibition of impulses, helplessness, } \\
\text { anxiousness, anger, embarrassment } \\
\text { intelligence, curiosity, learning valuable thing through } \\
\text { experience, breath of interest, creativity }\end{array}$ \\
\hline \multirow{2}{*}{ Openness to Experience }
\end{tabular}

In traditional terms intelligence is defined as the individuals' mental abilities in many terms. It could be emotional, social or even musical intelligence. These several types of intelligence could be useful to tackle the everyday events in the individuals' life. Emotional intelligence is described as the ability of individual's to monitor, manage and regulate their emotions and feelings well, during their day to day life (King \& Gardner 2006).

Amongst the definitions given by many researchers, the definition of Salovey and Mayer (1990) and Mayer and Salovey's (1997) is the most significant (Carmeli et al. 2009). Emotional intelligence is defined as "the subset of social intelligence that involves the ability to monitor one's own and others' feelings and emotions, to discriminate among them and to use this information to guide one's thinking and action" as per Salovey and Mayer (1990, p.189) was cited in (Carmeli et al. 2009). After seven years time the conceptualization of emotional intelligence was polished through introducing four dimensions. 


\section{Problem Statement}

Since the overall objective of this study is to find out whether there is a significant relationship between personality and emotional intelligence among the university community in Sri Lanka. Thus, the problem statement is as follows; "Is there a strong relationship between personality and emotional intelligence with regard to the university undergraduates in Sri Lanka?"

\section{Research Framework}

The relationship among the variables are depicted clearly in the theoretical framework, which guides this current research to find out the possible relationship among the university students' personality types and emotional intelligence. The hypotheses, which will be tested by the current research, are six (6). Figure 2 illustrates the conceptual framework of the study.

Figure 2: Expanded Model for the Relationship between Personality Type and Emotional Intelligence

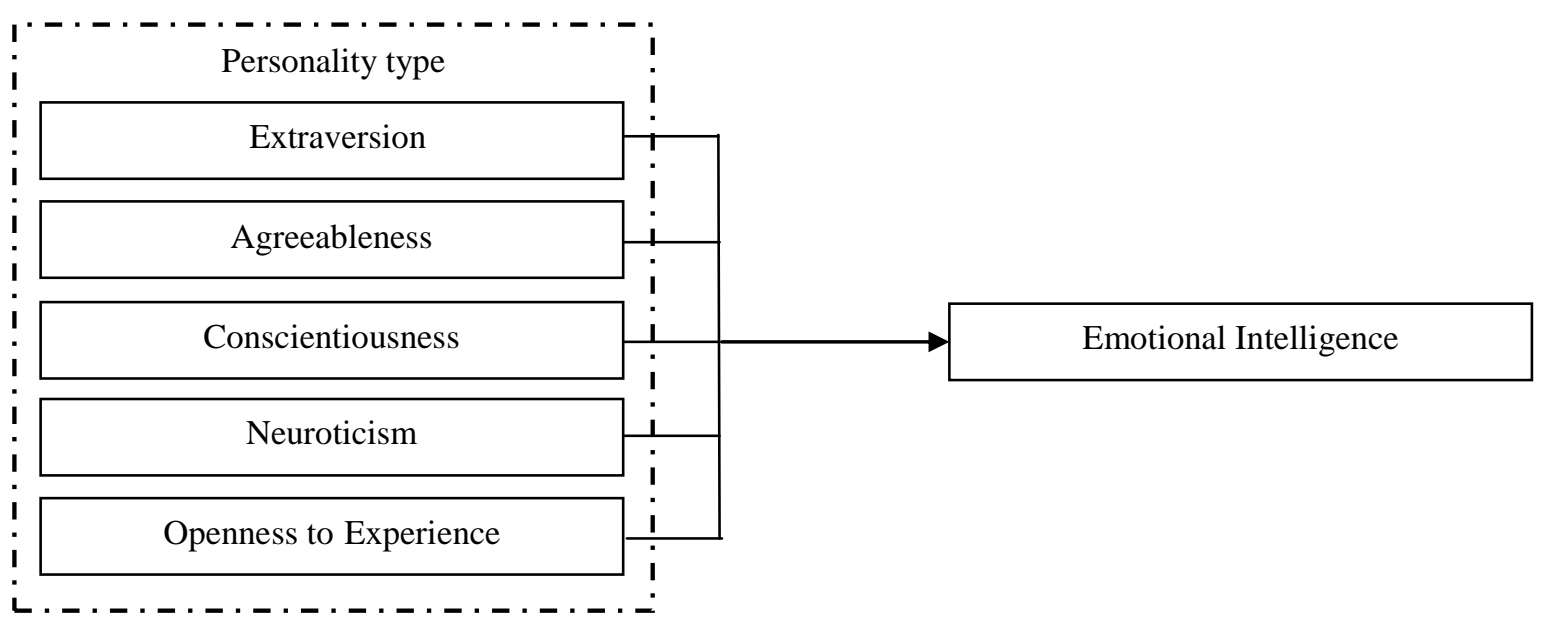

Van der Zee, Thijs and Schakel (2002) said that there is a relationship between personality and emotional intelligence. Therefore, as the null hypothesis of the current research it will be tested as there is no significant relationship between personality and emotional intelligence anticipating that this null hypothesis holds false. In other words, it is anticipated that there is a relationship between personality and emotional intelligence.

$H_{1}$ : There is no significant relationship between personality and emotional intelligence

According to the research by Leary et al. (2009), it was hypothesized that extraversion is positively associated with overall emotional intelligence. In their research, they investigated about the personality using MBTI and emotional intelligence was measured by using EQI dimensions. The results of their study supported this hypothesis. Based on Van Rooy and Viswesvaran (2004) and Petrides et al. (2007), it was found that the highest correlation of emotional intelligence was with extraversion. As cited in Van Der Zee et al. (2002), many previous studies have shown a relationship between emotional intelligence and extraversion. There is a significant and positive correlation between emotional intelligence, a research finding by Saklofske et al. (2003). In Sri Lankan context, a study by Kappagoda (2013) investigating the association between personality and emotional intelligence among Sri 
Lankan English school teachers, it was discovered, that the personality type extraversion of English teachers were significantly and positively correlated with their emotional intelligence. Thus in the current research, it is expected a positive relationship between extraversion and emotional intelligence among the university undergraduates.

$\mathrm{H}_{2}$ : Extraversion is positively associated with emotional intelligence.

The past studies Van Rooy and Viswesvaran (2004) investigating the correlation between personality and emotional intelligence revealed that there is a significant correlation between agreeableness and emotional intelligence. As cited Van Der Zee et al. (2002) in it was expected to be a positive relationship between agreeableness and emotional intelligence. Also, Saklofske et al. (2003) found that there is a positive correlation between those two variables, not only that Kappagoda (2013) study showed that in the Sri Lankan context it would have similar relationship between agreeableness and emotional intelligence. There in the current research it is predicted a positive relationship between agreeableness and emotional intelligence.

$H_{3}$ : Agreeableness is positively associated with emotional intelligence

There is a high correlation between conscientiousness and emotional intelligence (Van Rooy \& Viswesvaran 2004). As cited in Van Der Zee et al. (2002), it is found that a study by Van der Zee et al. (2000) found a significant relationship between conscientiousness and emotional intelligence. However, here in the study of Van Der Zee et al. (2002), it was expected that there was less possibility to have a relationship between conscientiousness and emotional intelligence considering that conscientiousness is nothing to do with monitoring and interpreting the owns or other's emotions, because it is concentred to be careful, reliable, persistent and goal directness. Nevertheless, a study done by Saklofske et al. (2003) was found that there is significant positive correlation between conscientiousness and emotional intelligence. Similar results were found by Kappagoda (2013). In the literature of the previous company, it is expected in the current study that there will be a positive relationship between conscientiousness and emotional intelligence among the university undergraduates.

\section{$\mathrm{H}_{4}$ : Conscientiousness is positively associated with emotional intelligence}

Emotional stability is the opposite of the neuroticism personality domain. While neuroticism is concentrated with the negative traits emotional stable individuals would have positive side of neuroticism. Studies by Van Rooy and Viswesvaran (2004), Van Der Zee et al. (2002) and Saklofske et al. (2003) found that there is a high correlation between emotional stability (opposite of neuroticism) and emotional intelligence. A Sri Lankan study about English school teachers revealed that there was a positive relationship between neuroticism and emotional intelligence among the English school teachers, even though it was anticipated as a negative relationship (Kappagoda 2013). Many past researches supported, that there would be a negative relationship between neuroticism and emotional intelligence. Therefore, it is expected a similar relationship in the current research as well.

$H_{5}$ : Neuroticism is negatively associated with emotional intelligence 
Fifth personality domain of big five - openness to experience is significantly correlated with emotional intelligence scores (Van Rooy \& Viswesvaran 2004). It was anticipated by Van Der Zee et al. (2002) there would be a positive correlation between openness and emotional intelligence. Similar results were found in the researches of Kappagoda (2013) and Saklofske, et al. (2003). There in the current study it is expected there will be a positive correlation between the fifth big five personality domain and emotional intelligence among the Sri Lankan university undergraduates.

$H_{6}:$ Openness to experience is positively associated with emotional intelligence

\section{Method}

Since this is a quantitative study, a research design which is adopted in quantitative studies been undertaken to conduct this research. The current research is to investigate whether there is a relationship between the personality type (independent variable) and the level of emotional intelligence (dependent variable) of the university students. This study involves the collection of quantitative data such as personality ratings, emotional intelligence ratings and identification data. This study will assist researcher to understand about the personality and emotional intelligence of the university undergraduates, reflect scientifically about the characteristics of the study been undertaken i.e. nature of the personality and emotional intelligence of the university undergraduates, put forward more thoughts and opinions for further researches in Sri Lankan context and assist to make certain decisions regarding the personality type and emotional intelligence of the Sri Lankan university undergraduates.

\section{Measure}

Paper and pencil questionnaire was used to collect the data and it included 77 items. The questionnaire was translated into Sinhala to avoid the misinterpretations and language difficulties. Since the questionnaire was administered personally and addressed each respondent individually, 100\% respondent rate was reported. The questions regarding big five personality dimensions were adopted from Big Five Inventory (BFI) (Jhon \& Srivastava 1999) while the emotional intelligence questionnaire was adapted from Schutte et al. (1998). The questionnaire was in 5 point Likert scales which rangeed from $1=$ Strongly Disagree to 5=Strongly Agree.

\section{Results}

The Pearson's Product Movement correlations of the variables are given in Table 01.

Table 01: Correlations between Variables

\begin{tabular}{|l|r|r|}
\hline & Pearson Correlation & Sig (2-tailed) \\
\hline Extraversion and Emotional Intelligence & .385 & .000 \\
\hline Agreeableness and Emotional Intelligence & .429 & .000 \\
\hline Conscientiousness and Emotional Intelligence & .462 & .000 \\
\hline Neuroticism and Emotional Intelligence & -.166 & .030 \\
\hline Openness to Experiences and Emotional Intelligence & .515 & .000 \\
\hline Big Five Personality and Emotional Intelligence & .577 & .000 \\
\hline
\end{tabular}


According to the correlation analysis (Table 1) between big five personality and emotional intelligence of the undergraduates is 0.577 , which is significant at the $1 \%$, (p: 0.000) level indicating that the correlation is statistically significant. Correlation between extraversion and emotional intelligence of the undergraduates is 0.385 which is significant at $1 \%$ (p: 0.000 ). 0.429 coefficient is recorded between the agreeableness and emotional intelligence of the undergraduates and it is also statistically significant. Between the conscientiousness and emotional intelligence of the university undergraduates is 0.462 which is significant at $1 \%$ (p: 0.000). As correlation coefficient between neuroticism and emotional intelligence of the undergraduates, there is a negative relationship (r: -0.166). Openness to experiences and emotional intelligence among the undergraduates record as a positive relationship ( $\mathrm{r}: 0.515$, p: 0.000).

The results of multiple regression analysis of the research model are given in Table 02 .

Table 2: Results of Multiple Regression Analysis

\begin{tabular}{|l|r|}
\hline R square & .412 \\
\hline Adjusted R square & .394 \\
\hline F & 23.232 \\
\hline Sig. & .000 \\
\hline Constant & .913 \\
\hline Extraversion & .098 \\
\hline Agreeableness & .185 \\
\hline Conscientiousness & .178 \\
\hline Neuroticism & .005 \\
\hline Openness to Experiences & .359 \\
\hline
\end{tabular}

The $\mathrm{R}$ square is 0.412 which is approximately $41 \%$ of the variability of emotional intelligence is explained by the model. In other words, the results shows that $41 \%$ of the variance or impact in emotional intelligence is significantly explained by the five independent variables of big five personality model.

\section{Discussion and Conclusion}

It was found that the overall big five personality dimensions positively correlated with the emotional intelligence, while extraversion, agreeableness, conscientiousness and openness to experience also positively correlated with emotional intelligence among the university undergraduates. Neuroticism is negatively correlated with emotional intelligence. The results of multiple regression analysis showed that the big five personality model can predict the variance of emotional intelligence by nearly from $41 \%$. Among the big five personality facets, agreeableness, conscientiousness, and openness to experience have a strong impact on the emotional intelligence of Sri Lankan undergraduates.

The result of moderately positive relationship between extraversion and emotional intelligence of the undergraduates can be provided the confirmatory evidence with Leary, Reilly and Brown (2009), Van Rooy and Viswesvaran (2004) and Saklofske, Austin and Minski (2003). The results of this study were shown that there is a moderate positive 
relationship between agreeableness and emotional intelligence among the university undergraduates. This result matched with Lopes, Salovey and Straus (2003), Van Rooy and Viswesvaran (2004), Petrides, Pita and Kokkinaki (2007) and Saklofske, Austin and Minski (2003). The results of this study revealed that there is a moderate positive relationship between conscientiousness and emotional intelligence of undergraduates. This finding collaborates with Van Rooy and Viswesvaran (2004) and Lopes, Salovey and Straus (2003). The most interestingly, the correlation analysis of the current research indicated that there is a modest negative relationship between neuroticism and emotional intelligence of the university undergraduates. This is supported by the studies done by Lopes, Salovey and Straus (2003), Petrides, Pita and Kokkinaki (2007) and Saklofske, Austin and Minski (2003). A strong positive relationship between openness to experiences and emotional intelligence among the university undergraduates and the studies such as Kappagoda (2013), Petrides, Pita and Kokkinaki (2007) and Saklofske, Austin and Minski (2003) and Van Rooy and Viswesvaran (2004) were reported the positive correlation between these two variables.

\section{Limitations}

A self-reporting questionnaire was used to determine the undergraduates' personality traits and the level of emotional intelligence. Due to self-rating, undergraduates might overrate or underrate their actual behaviour and traits with regard to the personality traits and emotional intelligence traits. There is a major possibility that the participants try to fake good or respond in a way, which is accepted by the society as the responds for self-report measures (Schutte et al. 1998) and self-rating EI measures only take its consideration on own view only (Kun et al. 2010). Therefore, the current research findings might also adversely affect the self-reporting questionnaire for some extent.

The size of the sample only consisted of the management undergraduates of the University of Sri Jayewardenepura and it might not be acknowledged as to generalize the research findings to the whole undergraduates' population of Sri Lanka. The sample size $(\mathrm{N}=172)$ might not also enough to generalise the findings to the management undergraduates of the University of Sri Jayewardenepura since it is not enough to reflect all strata among the undergraduates.

\section{References}

i. Alarcon, G, Eschleman, KJ \& Bowling, NA 2009, 'Relationtionship between personality variables and burnout: A meta analysis', Work \& Stress, vol. 23, no. 03, pp. 244-263.

ii. Bakker, A, Van Zee, K, Lewig, K \& Dollard, M 2006, 'The relationship between the big five personality factors and burnout: A study among voluenteer counselors', The Journal of Social Psychology, vol. 146, No. 1, pp. 31-50.

iii. Carmeli, A, Yitzhak-Halevy, M \& Weisberg, J 2009, 'The relationship between emotional intelligence and psychological wellbeing', Journal of Managerial Psychology, vol. 24, no. 01, pp. 66-78.

iv. Jhon, OP \& Srivastava, S 1999, 'The Big Five Trait Taxonomy: History, Measurement, and Theoretical Perspectives', In: Handbook of Personality: Theory and Research. New York: Guilford Press, pp. 102-138. 
v. Kappagoda, S 2013, 'The Relationship Between Emotional Intelligence And Five Factor Model Of Personality Of English Teachers In Sri Lanka', Kuala Lumpur, Malaysia, Proceeding - Kuala Lumpur International Business, Economics and Law Conference.

vi. Kim, M \& Unbreit, W 2007, 'Hotel job burnout: The role of personality characteristics', International Journal of Hospitality Management, Vol. 26, No. 2, pp. 421-434.

vii. King, M \& Gardner, D 2006, 'Emotional intelligence and occupational stress among professional staff in New Zealand', International Journal of Organizational Analysis, Vol. 14, No. 3, pp. 186-139.

viii. Kun, B, Balazs, H, Kapitany, M, Urban, R \& Demetrovics, Z 2010, 'Confirmations of the three factor model of the assessing emotional scale (AES): Verification of the theoretical standing point', Behaviour Research Methods, Vol. 42, No. 2, pp. 596606.

ix. Leary, MM, Reilly, MD \& Brown, FW 2009, 'A study of personality preferences and emotional intelligence', Leadership and Organiational Develpoment Journal, vol. 30, no. 5, pp. 421-434.

x. Leary, M, Reilly, M \& Brown, F 2009, 'A study of personality preferences and emotional intelligence', Leadership and Organizational Development Journal, Vol. 30, No. 5, pp.421-658.

xi. Lopes, P, Salovey, P \& Straus, R 2003, 'Emotional intelligence, personality, and the perceived quality of social relationship', Personality and Individual Differences, Vol. 35, No. 3, pp. 641-658.

xii. Opatha, HHDNP 2007, 'Individual Character: A Perspective', Sri Lankan Journal of Human esource Management, vol. 01, no. 01.

xiii. Petrides, K, Pita, R \& Kokkinaki, F 2007, 'The location of trait emotional intelligence in personality factor space', British Journal of Psychology, Vol. 98, No. 2, pp. 273289.

xiv. Saklofske, DH, Austin, EJ \& Minski, PS 2003, 'Factor structure and validity of a trait emotional intelligence measure', Personality and Individual Differences, vol. 34, pp. 707-721.

xv. Salovey, P \& Mayer, J 1990, 'Emotional intelligence', Imagination, Cognition and Personality', Vol. 9, pp. 185-211, viewed 1 august 2014.

xvi. Schutte, N, Malouff, J, Hall, L, Haggerty, D, Cooper, J, Golden, C \& Dornheim, L 1998, 'Development and validation of a measure of emotional intelligence', Personalityand Individual Difference, vol. 25, no. 2, pp. 167-177.

xvii. Van Der Zee, K, Thijs, M \& Schakel, L 2002, 'The Relationship of Emotional Intelligence with Academic Intelligence and the Big Five', European Journal of Personality, vol. 16, no. 2, pp. 103-125.

xviii. Van Rooy, DL \& Viswesvaran, C 2004, 'Emotional intelligence: A meta-analytic investigation of predictive validity and nomological net', Journal of Vocational Behavior, vol. 65, no. 1, pp. 71-95. 
Mallikaarachchi, CD

Department of Human Resource Management, University of Sri Jayewardenepura ish-upamali@yahoo.com

\section{Arachchige, BJH}

Senior Lecturer, Department of Human Resource Management, University of Sri Jayewardenepura bhadra@sjp.ac.lk, bhadra-arachchige@yahoo.com 